\title{
Espaçamento e adubação nitrogenada afetando o desenvolvimento do arroz de terras altas sob plantio direto
}

\author{
Orivaldo Arf', Ricardo Antônio Ferreira Rodrigues², Adriano Stephan Nascente ${ }^{*}$, Mábio Chrisley Lacerda ${ }^{4}$ \\ http://dx.doi.org/10.1590/0034-737X201562050008
}

\section{RESUMO}

A produtividade de grãos do arroz é resultante da interação entre o ambiente e o cultivar utilizado. Entre os fatores que influenciam essa produtividade estão o arranjo das plantas no campo e a adubação nitrogenada. O objetivo deste trabalho foi determinar os efeitos do espaçamento entre fileiras e da adubação nitrogenada na altura e acamamento de plantas, nos componentes de produção e produtividade e na qualidade industrial de grãos de arroz de terras altas, cultivado no sistema plantio direto. O experimento foi desenvolvido durante a safra agrícola 2010/ 2011, em condições de campo, no município de Selvíria, MS. O delineamento experimental foi em blocos completos casualizados, no esquema fatorial 2 x 4, com quatro repetições. Os tratamentos constaram de combinações entre os espaçamentos entre fileiras $(0,35$ e $0,50 \mathrm{~m})$ e as doses de $\mathrm{N}$ aplicadas na semeadura $\left(0,40,80\right.$ e $\left.120 \mathrm{~kg} \mathrm{ha}^{-1}\right)$. $\mathrm{O}$ menor espaçamento entre fileiras condicionou menor altura de plantas de arroz, maior número de panículas $\mathrm{m}^{-2}$, maior fertilidade das espiguetas e consequentemente maior produtividade de grãos de arroz. O incremento das doses de $\mathrm{N}$ na semeadura proporcionou maior altura e acamamento de plantas de arroz, ocasionando redução da produtividade e da massa hectolítrica de grãos da cultura. Espaçamento entre fileiras e nitrogênio não alteram a qualidade de grãos do arroz.

Palavras-chave: Oryza sativa L., nitrogênio, arranjo espacial de plantas, SPD, cerrado.

\begin{abstract}
Row spacing and nitrogen fertilization as affecting upland rice development under no-tillage

Rice grain yield is the result of the interaction between the environment and cultivar. One of the factors that influence yield is the arrangement of plants in the field and nitrogen fertilizer. The objective of the study was to determine the effect of row spacing and nitrogen fertilization on plant height and lodging, yield components, grain yield and quality of upland rice crop grown in a no-tillage system. The experiment was conducted during the growing season 2010/2011 under field conditions in Selvíria, MS, Brazil. The experimental design was a randomized complete block design in a factorial $2 \times 4$ with four replications. The treatments consisted of the combination of row spacing $(0.35$ and $0.50 \mathrm{~m})$ with the $\mathrm{N}$ rates applied at sowing $\left(0,40,80\right.$ and $\left.120 \mathrm{~kg} \mathrm{ha}^{-1}\right)$. The lower row spacing provided shorter rice plants, higher number of panicles $\mathrm{m}^{-2}$ and spikelet fertility and consequently higher grain yield of rice. The increased rates of $\mathrm{N}$ in the sowing provided taller rice plants and lodging, leading to reduced crop yield and hectoliter mass of grains. Row spacing and nitrogen did not affect grain quality of rice.
\end{abstract}

Key words: Oryza sativa L., nitrogen, plant spatial arrangement, NTS, Cerrado.

\footnotetext{
Submetido em 25/02/2014 e aprovado em 11/08/2015.

${ }^{1}$ Universidade Estadual Paulista, Faculdade de Engenharia de Ilha Solteira, Departamento de Fitotecnia, Tecnologia de Alimentos e Sócio-Economia, Ilha Solteira, São Paulo, Brasil. arf@agr.feis.unesp.br

${ }^{2}$ Universidade Estadual Paulista, Faculdade de Engenharia de Ilha Solteira, Departamento de Fitossanidade, Engenharia Rural e Solos, Ilha Solteira, São Paulo, Brasil. ricardo@agr.feis.unesp.br

${ }^{3}$ Embrapa Arroz e Feijão, Santo Antônio de Goiás, Goiás, Brasil. adriano.nascente @embrapa.br

${ }^{4}$ Embrapa Arroz e Feijão, Santo Antônio de Goiás, Goiás, Brasil. mabio.lacerda@embrapa.br

*Autor para correspondência: adriano.nascente@embrapa.br
} 


\section{INTRODUÇÃO}

$\mathrm{O}$ arroz faz parte da dieta de metade da população mundial (Kumar \& Ladha, 2011). A maior parte desse cereal é cultivada na Ásia, no sistema irrigado por inundação controlada (Farooq et al., 2009; Prasad, 2011). No entanto, a redução da disponibilidade dos recursos hídricos para a irrigação da cultura, por causa do aumento do consumo industrial e humano, tem exigido a busca por sistemas que possibilitem o cultivo do arroz com maior economia de água (Feng et al., 2007). Como alternativa, tem-se o cultivo do arroz no ecossistema terras altas, com irrigação por aspersão, ou em sequeiro, dependente da água da chuva (Nascente et al., 2013a). Neste sentido, tem-se o sistema plantio direto (SPD), que, por causa dos benefícios proporcionados aos produtores e ao ambiente, como maior conservação da umidade do solo, incremento da fertilidade e controle de plantas daninhas, vem apresentando grande expansão em sua utilização.

Para o cultivo do arroz em SPD ainda são necessários ajustes fitotécnicos, como o do espaçamento entre fileiras e o do manejo da adubação nitrogenada, visando à maior produtividade de grãos (Carvalho et al., 2008). O espaçamento adequado depende da interação entre o cultivar e o ambiente. Para a cultura do arroz de terras altas, com preparo convencional do solo (uma aração e duas gradagens), recomenda-se o espaçamento na faixa de 40 a $50 \mathrm{~cm}$ entre fileiras e densidade de semeadura de 60 a 70 sementes, por metro (Santos et al., 2006). Entretanto, com o lançamento de cultivares modernos de folhas eretas e altura intermediária, necessário se faz o estudo do espaçamento adequado, no SPD, uma vez que, nesse sistema, as plantas normalmente apresentam crescimento mais lento, o que favorece a infestação por plantas daninhas, com reflexos negativos na produtividade de grãos (Nascente et al., 2013b). Por exemplo, para o cultivar BRSMG Conai, Carvalho et al. (2008) constataram que a maior produtividade de grãos foi obtida com o espaçamento de 0,30 $\mathrm{m}$. Dessa forma, no SPD pode ser necessário um menor espaçamento, visando a evitar a infestação de plantas daninhas e a redução de produtividade e proporcionar maior aproveitamento dos recursos do meio (Jadoski et al., 2000).

A aplicação de maior quantidade de nitrogênio, na semeadura, com espaçamento reduzido, pode proporcionar um arranque inicial de plantas mais rápido, com fechamento entre fileiras, reduzindo a infestação por plantas daninhas (Kluthcouski et al., 2006). Entretanto, se por um lado é relatado que o nitrogênio proporciona incrementos significativos da produtividade de grãos do arroz de terras altas (Arf et al., 2005; Cazetta et al., 2008; Cancellier et al., 2011; Nascente et al., 2011), por outro lado, utilizando-se doses de nitrogênio maiores que as necessárias, podem-se criar condições que favoreçam o crescimento exagerado das plantas e, consequentemente, aumentar o acamamento (Arf et al., 2005; Nascimento et al., 2009; Alvarez et al., 2012). Além disso, o excesso de $\mathrm{N}$ pode proporcionar o desenvolvimento de doenças e afetar a produtividade e a qualidade dos grãos (Crusciol et al., 2006; Marzari et al., 2007).

A combinação adequada do espaçamento entre fileiras com a dose de nitrogênio pode proporcionar incrementos significativos da produtividade e da qualidade de grãos do arroz de terras altas. Entretanto, ainda são poucos os trabalhos avaliando essas duas variáveis, principalmente, para os cultivares com tipos de plantas intermediárias (plantas de porte relativamente alto e susceptíveis ao acamamento, quando cultivadas em solos férteis, ou quando adubadas com altas doses de N) e modernas (plantas de porte menor e menos susceptíveis ao acamamento). Assim, o objetivo deste trabalho foi determinar os efeitos do espaçamento entre fileiras e da adubação nitrogenada na altura e no acamamento de plantas, nos componentes de produção, na produtividade e na qualidade industrial de grãos de arroz de terras altas, cultivado no sistema plantio direto.

\section{MATERIAL E MÉTODOS}

$\mathrm{O}$ experimento foi realizado durante a safra agrícola 2010/2011, no município de Selvíria, MS, situado aproximadamente a $51^{\circ} 22^{\prime} \mathrm{O}$ e $20^{\circ} 22^{\prime} \mathrm{S}$, com altitude de 335 metros. O solo do local é do tipo Latossolo Vermelho distrófico argiloso (EMBRAPA, 2013). Antes da instalação do experimento foram coletadas amostras para a caracterização química do solo (Tabela 1). A precipitação média anual é de $1.370 \mathrm{~mm}$, a temperatura média anual é de $23,5^{\circ} \mathrm{C}$ e a umidade relativa do ar entre 70 e 80\% (média anual) (INPE, 2014). Adicionalmente, foi feita a avaliação periódica dos dados de temperatura e precipitação na área experimental (Figura 1). O experimento foi instalado em área sob sistema plantio direto há seis anos, tendo como culturas anteriores soja em rotação com milho, no verão, e feijão, no inverno.

O delineamento experimental foi em blocos completos casualizados, no esquema fatorial $2 \times 4$, com quatro repetições. Os tratamentos constaram da combinação entre o espaçamento entre fileiras $(0,35$ e $0,50 \mathrm{~m})$ e as doses de $\mathrm{N}$ aplicadas na semeadura $(0,40,80$ e 120 $\left.\mathrm{kg} \mathrm{ha}^{-1}\right)$. As parcelas foram constituídas por dez linhas de $5 \mathrm{~m}$ de comprimento. A área útil foi constituída pelas linhas centrais, desprezando-se duas linhas laterais e 0,50 $\mathrm{m}$ em ambas das extremidades de cada linha. 
Aproximadamente 15 dias antes da semeadura, a vegetação espontânea da área de cultivo foi dessecada com os herbicidas Glyphosate + 2,4 D. A semeadura da linhagem mutante 07SEQCL441 CL, derivada do cultivar Primavera CL, que apresenta um gene de resistência ao herbicida Imazapir + Imazapique (Kifix), foi realizada, mecanicamente no dia 21/12/2010 utilizando-se $80 \mathrm{~kg}$ $\mathrm{ha}^{-1}$ de sementes, ou seja, a população de plantas por área nos dois espaçamentos foi a mesma (160 e 112 sementes $\mathrm{m}^{-1}$, nos espaçamentos de 0,50 e $0,35 \mathrm{~m}$, respectivamente). Antes da semeadura, as sementes foram tratadas com Carboxina + Tiram (Vitavax + Thiram) (250 mL 100 $\mathrm{kg}$ de sementes $\left.{ }^{-1}\right)+$ Cinetina + ácido giberélico + ácido 4-indol-3-ilbutírico (Stimulate) (5mL kg de sementes ${ }^{-1}$ ) + Piraclostrobina + Tiofanato metílico + Fipronil (Standak Top) (150 mL $100 \mathrm{~kg}$ de sementes $\left.{ }^{-1}\right)+$ Fipronil (Standak) (100ml 100kg de sementes ${ }^{-1}$ ).

A adubação básica nos sulcos de semeadura, constituída de $50 \mathrm{~kg} \mathrm{ha}^{-1}$ de $\mathrm{K}_{2} \mathrm{O}$ (cloreto de potássio) e $50 \mathrm{~kg}$ ha $^{-1}$ de $\mathrm{P}_{2} \mathrm{O}_{5}$ (superfosfato triplo), foi calculada de acordo com as características químicas do solo (Tabela 1) e levando-se em consideração as recomendações de Cantarella \& Furlani (1996). A adubação nitrogenada de semeadura foi realizada de acordo com os respectivos tratamentos. A adubação de cobertura com $40 \mathrm{~kg} \mathrm{ha}^{-1} \mathrm{de}$
$\mathrm{N}$ (ureia), foi realizada, em todos os tratamentos, aos 21 dias após a emergência da cultura. Logo após a aplicação de nitrogênio, a área foi irrigada com aproximadamente $10 \mathrm{~mm}$ de água, com o objetivo de minimizar as perdas de $\mathrm{N}$ por volatilização.

Durante o experimento, a área foi irrigada, quando necessário, com sistema de irrigação por aspersão autopropelido, com precipitação média de $10 \mathrm{~mm}$ hora $^{-1}$. Para o manejo de água, foram utilizados três coeficientes de cultura $(\mathrm{Kc})$, distribuídos em quatro períodos compreendidos entre a emergência e a colheita. Para a fase vegetativa, foi utilizado o valor de 0,4 ; para a fase reprodutiva dois coeficientes de cultura, o inicial de 0,70 e o final de 1,00 e, para a fase de maturação, esses valores foram invertidos, ou seja, o inicial de 1,00 e o final de 0,70 (Rodrigues et al., 2004).

O controle de plantas daninhas foi realizado com os herbicidas Imazapir + Imazapique (Kifix) (100 $\mathrm{g} \mathrm{ha}^{-1} \mathrm{e}$ $50 \mathrm{~g} \mathrm{ha}^{-1}$ do produto comercial), aos 16 e 26 dias após a emergência das plantas, respectivamente. Não foi necessária a adoção de medidas de controle para pragas e doenças da parte aérea das plantas.

As avaliações realizadas foram: da altura de plantas (m), durante o estádio de grãos na forma pastosa, determinada em dez plantas ao acaso, na área útil de cada par-

Tabela 1: Resultados de análise química do solo, na camada de 0-0,20 m da área experimental. Safra 2010/2011

\begin{tabular}{|c|c|c|c|c|c|c|c|c|c|}
\hline $\mathbf{P}_{\text {resina }}$ & M.O. & pH & $\mathbf{K}$ & $\mathrm{Ca}$ & Mg & $\mathbf{H}+\mathbf{A l}$ & Al & CTC & $\mathbf{V}$ \\
\hline $\mathrm{mg} \mathrm{dm}^{-3}$ & $\mathrm{~g} \mathrm{dm}^{-3}$ & $\left(\mathrm{CaCl}_{2}\right)$ & \multicolumn{6}{|c|}{$\mathrm{mmol}_{\mathrm{c}} \mathrm{dm}^{-3}$} & $(\%)$ \\
\hline 17 & 13 & 5,2 & 2,9 & 33 & 14 & 27 & 0 & 77 & 65 \\
\hline
\end{tabular}



Figura 1: Precipitação pluvial, temperatura (T) mínima, temperatura máxima e umidade relativa(UR) da área experimental, durante o período de condução do experimento. Selvíria (MS) Brasil, safra 2010/2011. 
cela, da superfície do solo até a extremidade superior da panícula mais alta; do grau de acamamento, por meio de observações visuais na fase de maturação, utilizando-se escala de notas: 0 - sem acamamento; 1 - até $5 \%$ de plantas acamadas; 2 - 5 a 25\%, 3 - 25 a 50\%; $4-50$ a $75 \%$ e $5-75$ a $100 \%$ de plantas acamadas; do número de panículas por metro quadrado, pela contagem do número de panículas em 1,0 m de fileira de plantas na área útil das parcelas e, por regra de três, fazendo-se o cálculo por área. A avaliação do número total de grãos por panícula feita por contagem do número de grãos de 20 panículas coletadas no momento da colheita, em cada parcela; avaliação da fertilidade das espiguetas, determinada pela divisão do número de grãos cheios de 20 panículas pelo número total de grãos.

A maturação da cultura foi definida quando ocorreu a maturação de $90 \%$ das panículas da parcela; a massa de 100 grãos, pela coleta, ao acaso, e pesagem de duas amostras de 100 grãos de cada parcela (13\% base úmida); a massa hectolítrica, pela pesagem de uma amostra de 0,25 litros de grãos de cada parcela, correção dos valores para $13 \%$ base úmida e conversão para $\mathrm{kg} 100 \mathrm{~L}^{-1}$; a produtividade de grãos, pela pesagem dos grãos em casca, de todas as plantas da área útil das parcelas, incluindo-se as acamadas, e correção da umidade para $13 \%$.

$\mathrm{O}$ rendimento industrial foi determinado, coletandose amostra de $100 \mathrm{~g}$ de grãos de arroz em casca de cada parcela, a qual foi processada em engenho de prova, por um minuto; em seguida, os grãos brunidos (polidos) foram pesados e o valor encontrado foi considerado como rendimento de benefício, sendo os resultados expressos em percentagem. Posteriormente, os grãos brunidos (polidos) foram colocados no "Trieur" $\mathrm{n}^{\mathrm{o}} 2$ e sua separação foi processada por 30 segundos; os grãos que permaneceram no "Trieur" foram pesados, obtendo-se o rendimento de inteiros e os demais, grãos quebrados, ambos expressos em percentagem.

Os dados foram submetidos à análise de variância e, quando necessário, foi realizado o teste comparativo de médias Tukey, para $\mathrm{p}<0,05$. Para análise do efeito das doses de nitrogênio, foi utilizada a análise de regressão para $\mathrm{p}<0,05$. No processamento dos dados foi utilizado o programa estatístico SAS.

\section{RESULTADOS E DISCUSSÃO}

$\mathrm{O}$ espaçamento entre fileiras alterou a altura e o acamamento de plantas (Tabela 2). No menor espaçamento $(0,35 \mathrm{~m})$ verificou-se menor altura de plantas $(125,6 \mathrm{~cm})$ do que no maior espaçamento $(0,50 \mathrm{~m})$, em que a altura foi de 1,30 m. Esse resultado pode ser reflexo da maior competição entre as plantas no maior espaçamento, uma vez que a população por metro qua- drado foi a mesma nos dois espaçamentos, assim no maior espaçamento havia maior número de plantas na linha e maior competição entre elas. Segundo Jadoski et al. (2000) e Freitas et al. (2013), o maior número de plantas acarreta aumento da competição por luz e fotoassimilados entre elas.

Em relação ao nitrogênio, constata-se que as doses crescentes do nutriente proporcionaram incrementos significativos da altura de plantas, com ajuste dos dados à equação linear (Figura 2). Segundo Arf et al. (2005), o nitrogênio é o nutriente que mais afeta a altura de plantas. Corroborando essas informações, Buzetti et al. (2006), Hernandes et al. (2010) e Mattje et al. (2013) também obtiveram incrementos significativos da altura de plantas de arroz com o aumento das doses de N.

Com relação ao acamamento de plantas, houve interação entre os fatores espaçamento e doses de $\mathrm{N}$ (Tabela 2). Os dados seguiram tendência quadrática, para os dois espaçamentos, com menores notas no maior espaçamento (Figura 3). Com base nos resultados, podese inferir que o $\mathrm{N}$ também influenciou diretamente essa característica, sendo que, na ausência da aplicação desse nutriente (tratamento controle), as notas de acamamento foram as menores. O nitrogênio pode tornar as plantas mais susceptíveis ao acamamento, como relatado por Fidelis et al. (2012). Esses resultados são importantes, pois a maior quantidade de nitrogênio proporcionou aumento das notas de acamamento de plantas, o que não é vantajoso do ponto de vista do produtor, pela perda de grãos na colheita.

Com relação aos componentes de produção, constata-se que o número de panículas $\mathrm{m}^{-2}$ e a fertilidade das espiguetas foram afetados significativamente pelo

Tabela 2: Altura e notas de acamamento de plantas de arroz de terras altas cultivadas no SPD, em função do espaçamento entre fileiras e das doses de nitrogênio. Safra 2010/2011

\begin{tabular}{lcc}
\hline Tratamentos & Altura & Acamamento \\
\hline Espaçamento & $\mathbf{c m}$ & nota \\
\hline $0,35 \mathrm{~m}$ & $125,6 \mathrm{~b}^{1}$ & 4,81 \\
$0,50 \mathrm{~m}$ & $130,0 \mathrm{a}$ & 4,50 \\
\hline Doses de $\mathbf{N}$ & & \\
\hline 0 & 121,6 & 3,62 \\
$40 \mathrm{~kg} \mathrm{ha}^{-1}$ & 126,7 & 5,00 \\
$80 \mathrm{~kg} \mathrm{ha}^{-1}$ & 128,0 & 5,00 \\
$120 \mathrm{~kg} \mathrm{ha}^{-1}$ & 134,7 & 5,00 \\
\hline Fatores & Anava - Probabilidade do teste $\mathbf{F}$ \\
\hline Espaçamento (E) & $5,28^{*}$ & $6,18^{*}$ \\
Doses de N (N) & $7,82^{* *}$ & $33,00^{* *}$ \\
E x N & 1,50 & $6,81^{* *}$ \\
\hline
\end{tabular}

${ }^{1}$ Médias seguidas pela mesma letra minúscula na coluna não diferem entre si pelo teste de Tukey para $p<0,05$. 
espaçamento (Tabela 3). O menor espaçamento proporcionou maiores valores para essas características, em comparação com o maior espaçamento. Segundo Jadoski et al. (2000), a redução do espaçamento, dentro de certos limites, proporciona arranjo mais equidistante entre plantas, de forma a reduzir a competição por recursos do ambiente, explorando de forma mais completa e eficiente uma determinada área do solo. Nesse sentido, verifica-se que o menor espaçamento acarretou incremento do número de panículas por área $\left(\mathrm{m}^{-2}\right)$. De acordo com Freitas et al. (2013), a utilização de maior espaçamento entre fileiras acarreta a redução da eficiência de interceptação da radiação solar por área e pode proporcionar aumento da produção por planta, havendo, entretanto, redução da produtividade por área. Por outro lado, o menor espaçamento (maior número de plantas por área) proporciona maior produção por área e redução da produtividade por indivíduo.

No componente de produção número de espiguetas por panícula, verificou-se o inverso, ou seja, maiores valores no espaçamento $0,50 \mathrm{~m}$ (165) do que no espaçamento 0,35 m (139) (Tabela 3). Quando se aumenta o número de panículas (de 186 para 254) há efeito compensatório entre os componentes de produção e isso resultou na redução do tamanho da panícula, o que pode resultar em menor número de espiguetas (Santos et al., 2006).

A produtividade de grãos de arroz é determinada por quatro componentes: o número de panículas $\mathrm{m}^{-2}$, o número de espiguetas panícula ${ }^{-1}$, a fertilidade das espiguetas e a massa de 1000 grãos (Yoshida, 1981). Assim, a partir dos resultados obtidos no número de panículas $\mathrm{m}^{-2} \mathrm{e}$ na fertilidade das espiguetas, esperava-se que o cultivo do arroz no espaçamento de $0,35 \mathrm{~m}$ proporcionasse a maior produtividade de grãos, o que foi confirmado, pois com esse espaçamento constataram-se os maiores valores (4.120 $\mathrm{kg} \mathrm{ha}^{-1}$ ) (Tabela 3). Carvalho et al. (2008) também observaram maior produtividade de grãos para o cultivar BRSMG Conai no menor espaçamento $(0,30$ $\mathrm{m})$, em detrimento do maior espaçamento $(0,40 \mathrm{~m})$.

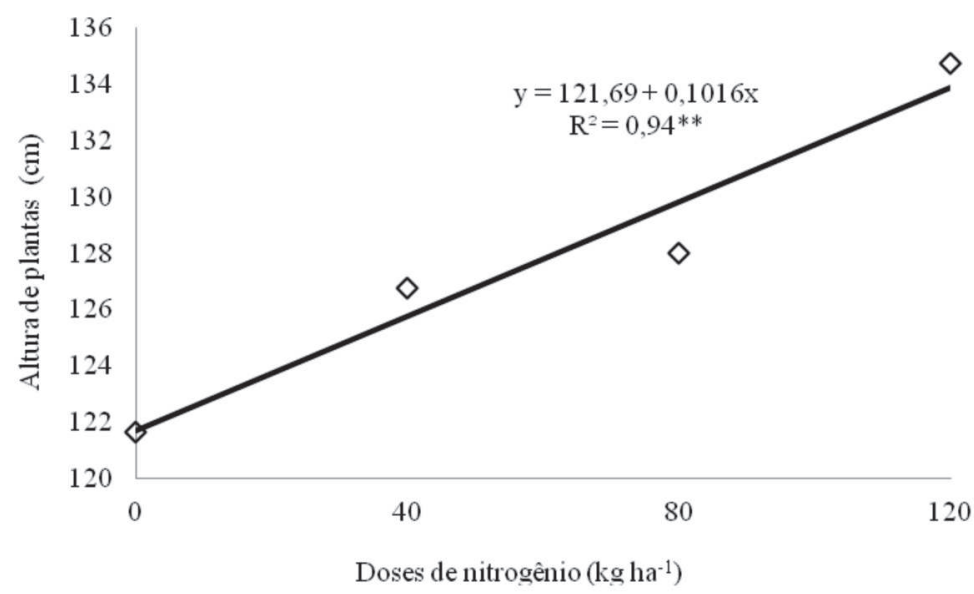

Figura 2: Altura de plantas de arroz, em função de doses de nitrogênio aplicadas na semeadura. Safra 2010/2011.

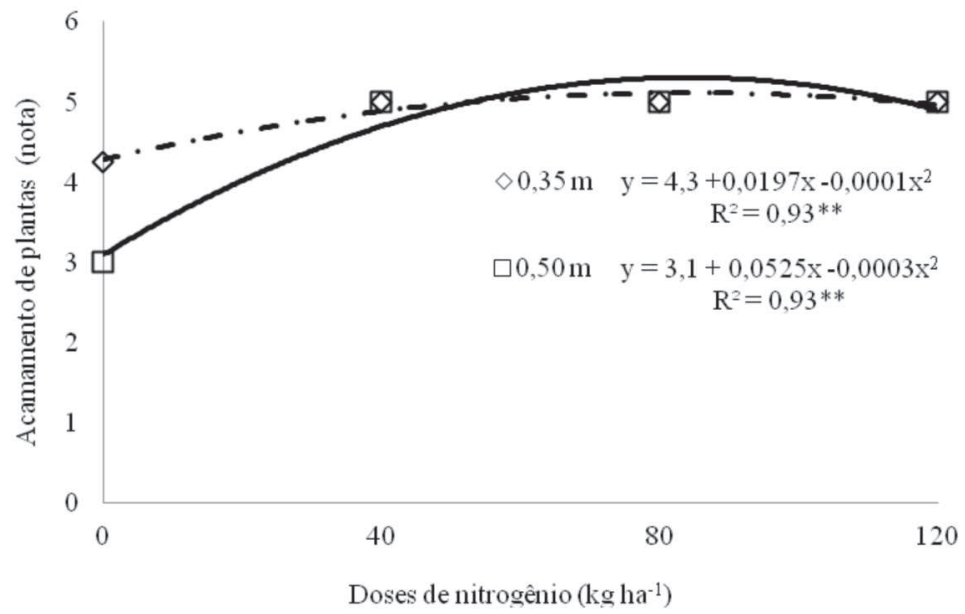

Figura 3: Interação do acamamento de plantas de arroz, em função de doses de nitrogênio aplicadas na semeadura e do espaçamento entre fileiras utilizado. Safra 2010/2011. 
Avaliando-se o efeito das doses de nitrogênio na produtividade de grãos, constata-se que houve efeito linear negativo, ou seja, quando se aumentou a dose de $\mathrm{N}$ ocorreu redução da produtividade de grãos (Figura 4). $\mathrm{O}$ aumento das doses de $\mathrm{N}$ normalmente proporciona incrementos significativos da produtividade de grãos do arroz, conforme relatado por diversos autores (Arf et al., 2005; Cazetta et al., 2008; Cancellier et al., 2011; Nascente et al., 2011). Entretanto, especial atenção deve ser dada à escolha dos cultivares, pois, maiores quantidades de $\mathrm{N}$ proporcionam maior acamamento (Tabela 2), que dificulta a translocação de fotoassimilados para o enchimento de grãos e resulta em quedas significativas de produtividade (Crusciol et al., 2006; Santos et al., 2006; Marzari et al., 2007). Segundo Arf et al. (2005), a aplicação de maiores doses de nitrogênio na semeadura pode proporcionar aumento do crescimento vegetativo das plantas de arroz e ocasionar redução da produtividade da cultura, por causa do acamamento.

Nesse sentido, a linhagem utilizada, que é derivada do cultivar BRS Primavera, apresenta porte intermediário e susceptibilidade ao acamamento e, em caso de se utilizarem doses maiores de $\mathrm{N}$, devem-se buscar alternativas para proporcionar a redução do crescimento das plantas e evitar o acamamento. Uma alternativa poderia ser a utilização de redutores de crescimento de plantas, que proporcionam redução da altura e, na maioria dos casos, não causam redução da produtividade da cultura, como relatado por diversos autores (Buzetti et al., 2006; Nascimento et al., 2009; Alvarez et al., 2012; Arf et al., 2012).

O espaçamento entre fileiras não alterou a massa hectolítrica, o rendimento de benefício e o rendimento de grãos inteiros e de grãos quebrados (Tabela 4). A presença de grãos quebrados num lote de grãos arroz

Tabela 3: Número de panículas $\mathrm{m}^{-2}$ (PAN), número de espiguetas por panícula (NESP), fertilidade das espiguetas (FERT), massa de 100 grãos (MGRAO) e produtividade de grãos (PROD) do arroz de terras altas, cultivado no SPD, em função do espaçamento entre fileiras e das doses de nitrogênio. Safra 2010/2011

\begin{tabular}{|c|c|c|c|c|c|}
\hline Tratamentos & PAN & NESP & FERT & MGRAO & PROD \\
\hline Espaçamento & $\mathbf{n}^{0} \mathbf{m}^{-2}$ & número & $\%$ & gramas & $\mathrm{kg} \mathrm{ha}^{-1}$ \\
\hline $0,35 \mathrm{~m}$ & $254 \mathrm{a}^{1}$ & $139 \mathrm{~b}$ & $83,21 \mathrm{a}$ & 3,00 & $4.120 \mathrm{a}$ \\
\hline $0,50 \mathrm{~m}$ & $186 \mathrm{~b}$ & $165 \mathrm{a}$ & $79,86 \mathrm{~b}$ & 2,88 & $3.728 \mathrm{~b}$ \\
\hline \multicolumn{6}{|l|}{ Doses de N } \\
\hline 0 & 229 & 171 & 78,52 & 3,00 & 4.456 \\
\hline $40 \mathrm{~kg} \mathrm{ha}^{-1}$ & 233 & 144 & 84,50 & 3,00 & 4.112 \\
\hline $80 \mathrm{~kg} \mathrm{ha}^{-1}$ & 207 & 138 & 87,54 & 2,88 & 3.455 \\
\hline $120 \mathrm{~kg} \mathrm{ha}^{-1}$ & 212 & 156 & 76,24 & 3,00 & 3.673 \\
\hline Fatores & \multicolumn{5}{|c|}{ Anava - Probabilidade do teste $F$} \\
\hline Espaçamento (E) & $20,46^{* *}$ & $4,74 *$ & $4,34 *$ & $1,91 \mathrm{~ns}$ & $3,71^{*}$ \\
\hline Doses de $N(N)$ & $0,71 \mathrm{~ns}$ & $1,56 \mathrm{~ns}$ & $0,84 \mathrm{~ns}$ & $0,64 \mathrm{~ns}$ & $4,87^{*}$ \\
\hline$E \times N$ & $0,57 \mathrm{~ns}$ & $2,24 \mathrm{~ns}$ & $1,64 \mathrm{~ns}$ & $0,64 \mathrm{~ns}$ & $0,09 \mathrm{~ns}$ \\
\hline
\end{tabular}

${ }^{1}$ Médias seguidas pela mesma letra minúscula na coluna não diferem entre si pelo teste de Tukey para $p<0,05$.



Figura 4: Produtividade de grãos do arroz de terras altas, em função de doses de nitrogênio aplicadas na semeadura. Safra 2010/2011. 
é característica indesejável, pois diminui a qualidade e o valor comercial do produto. Além da redução do valor econômico, pode ocorrer, também, a diminuição da quantidade total de grãos descascados (rendimento de benefício), pois frações de grãos podem ser eliminadas junto com as cascas (Crusciol et al., 2006). Esses autores relatam que, apesar de as causas que determinam a qualidade do grão não estarem bem elucidadas, sabe-se que o manejo inadequado da lavoura, como o controle ineficiente de pragas, as doenças e as plantas daninhas, a colheita na época inadequada e a secagem muito rápida ou muito lenta dos grãos têm influência direta nesse atributo. Dessa forma, verifica-se que nem o espaçamento entre fileiras, nem as doses de $\mathrm{N}$ alteraram a qualidade do grão de arroz.

Por outro lado, a massa hectolítrica foi afetada pelas doses de $\mathrm{N}$, sendo os dados ajustados para equação linear quadrática (Figura 5). Teixeira Filho et al. (2010), na cultura do trigo, também relataram comportamento linear decrescente da massa hectolítrica, em consequência do aumento das doses de N. A massa hectolítrica correspondente à massa de grãos em $\mathrm{kg} \mathrm{em}$ um volume de $100 \mathrm{~L}$, determinada em balança de $1 / 4$, com teor de água dos grãos corrigido para 13\% (base úmida) (Megda et al., 2009). Segundo os autores, o fornecimento de $\mathrm{N}$ juntamente com a irrigação está entre os principais fatores que alteram a massa hectolítrica, proporcionando um longo período de enchimento de grãos, elevando a massa hectolítrica e a produtividade de grãos. Entretanto, por causa do acamamento observado nos tratamentos com maiores quantidades de $\mathrm{N}$, houve comprometimento desse fluxo contínuo, com efeitos significativos e negativos para a produtividade (Figura 4) e para a massa hectolítrica (Figura 5).

Tabela 4: Massa hectolítrica (MHEC), rendimento de benefício (RBEN), rendimento de grãos inteiros (RGI) e grãos quebrados (GQ) de plantas de arroz de terras altas, cultivadas no SPD, em função do espaçamento entre fileiras e das doses de nitrogênio. Safra 2010/ 2011

\begin{tabular}{|c|c|c|c|c|}
\hline \multirow{2}{*}{$\begin{array}{l}\text { Tratamentos } \\
\text { Espaçamento }\end{array}$} & MHEC & RBEN & RGI & GQ \\
\hline & kg $100 \mathrm{~L}^{-1}$ & \multicolumn{3}{|c|}{$\%$} \\
\hline $0,35 \mathrm{~m}$ & 49,25 & 68,56 & 59,44 & 9,12 \\
\hline 0,50 & 50,37 & 69,50 & 60,75 & 8,50 \\
\hline \multicolumn{5}{|l|}{ Doses de $N$} \\
\hline 0 & 51,75 & 70,25 & 63,25 & 7,25 \\
\hline $40 \mathrm{~kg} \mathrm{ha}^{-1}$ & 51,00 & 70,25 & 61,75 & 9,63 \\
\hline $80 \mathrm{~kg} \mathrm{ha}^{-1}$ & 49,25 & 67,63 & 56,75 & 9,25 \\
\hline $120 \mathrm{~kg} \mathrm{ha}^{-1}$ & 47,25 & 68,00 & 58,63 & 9,12 \\
\hline Fatores & \multicolumn{4}{|c|}{ Anava - Probabilidade do teste $F$} \\
\hline Espaçamento (E) & $1,18 \mathrm{~ns}$ & $0,51 \mathrm{~ns}$ & $0,46 \mathrm{~ns}$ & $0,51 \mathrm{~ns}$ \\
\hline Doses de $N(\mathrm{~N})$ & $3,76^{*}$ & $0,17 \mathrm{~ns}$ & $2,34 \mathrm{~ns}$ & $1,48 \mathrm{~ns}$ \\
\hline $\mathrm{E} \times \mathrm{N}$ & $0,64 \mathrm{~ns}$ & $0,40 \mathrm{~ns}$ & $0,62 \mathrm{~ns}$ & $0,61 \mathrm{~ns}$ \\
\hline
\end{tabular}

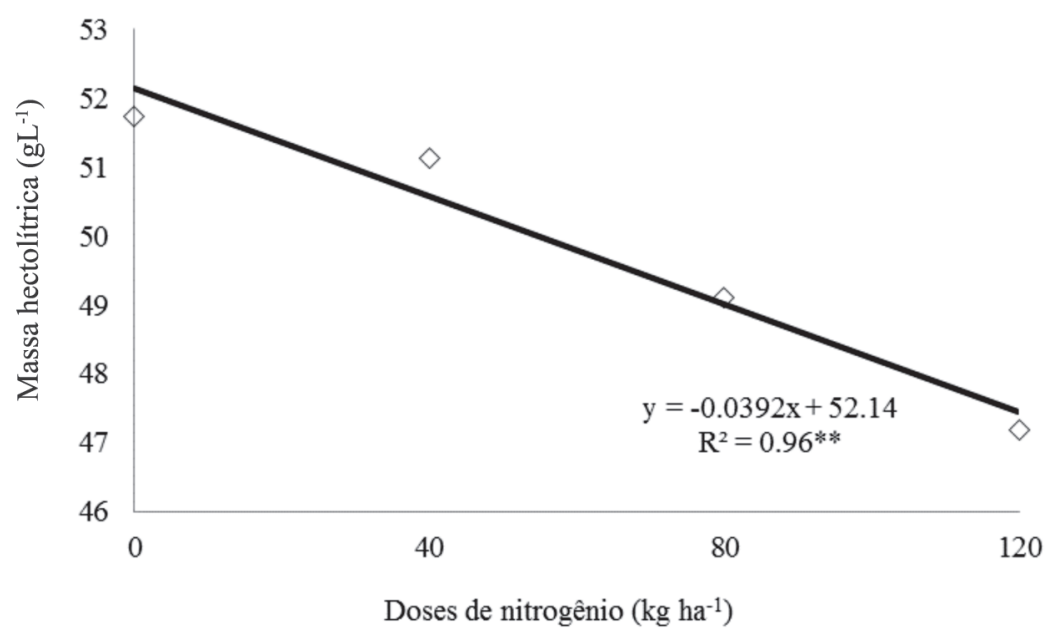

Figura 5: Massa hectolítrica de grãos do arroz de terras altas, em função de doses de nitrogênio aplicadas na semeadura. Safra 2010/ 2011. 


\section{CONCLUSÕES}

O menor espaçamento $(0,35 \mathrm{~m})$ proporciona menor altura de plantas de arroz, maior número de panículas $\mathrm{m}^{-2}$, maior fertilidade das espiguetas e, consequentemente, maior produtividade de grãos de arroz.

$\mathrm{O}$ incremento das doses de $\mathrm{N}$ na semeadura proporciona maior altura e maior acamamento de plantas de arroz, ocasionando redução da produtividade e da massa hectolítrica de grãos da cultura.

O espaçamento entre fileiras e as doses de nitrogênio não alteram a qualidade industrial de grãos do arroz.

\section{REFERÊNCIAS}

Alvarez RCF, Crusciol CAC, Nascente AS, Rodrigues JD \& Habermann G (2012) Gas exchange rates, plant height, yield components, and productivity of upland rice as affected by plant regulators. Pesquisa Agropecuária Brasileira, 47:1455-1461.

Arf O, Bastos JCHAG, Silva MG, Sá ME, Rodrigues RAF \& Buzetti S (2005) Manejo do solo e época de aplicação de nitrogênio na produção de arroz de terras altas. Acta Scientiarum Agronomy, 27:215-223.

Arf O, Nascimento V, Rodrigues RAF, Alvarez RCF, Gitti DC \& Sá ME (2012) Uso de etil-trinexapac em cultivares de arroz de terras altas. Pesquisa Agropecuária Tropical, 42:150-158.

Buzetti S, Bazanini GC, Freitas JG, Andreotti M, Arf O, Sá ME \& Meira FA (2006) Resposta de cultivares de arroz a doses de nitrogênio e do regulador de crescimento cloreto de clormequat. Pesquisa Agropecuária Brasileira, 41:1731-1737.

Cancellier EL, Barros BH, Kischel E, Gonzaga LAM, Brandão DR \& Fidelis RR (2011) Eficiência agronômica no uso de nitrogênio mineral por cultivares de arroz de terras altas. Ciências Agrárias, 6:650-656.

Cantarella H \& Furlani PR (1996) Arroz de sequeiro. In: Raij B Van, Cantarella H, Guaggio JA \& Furlani AMC (Eds.) Recomendações de Adubação e Calagem para o Estado de São Paulo. $2^{\mathrm{a}}$ ed. Campinas, Instituto Agronômico. p.48-49. (Boletim técnico, 100).

Carvalho JA, Soares AA \& Reis MS (2008) Efeito de espaçamento e densidade de semeadura sobre a produtividade e os componentes de produção da cultivar de arroz BRSMG Conai. Ciência e Agrotecnologia, 32:785-791.

Cazetta DA, Arf O, Buzetti S, Sá ME \& Rodrigues RAF (2008) Desempenho do arroz de terras altas com a aplicação de doses de nitrogênio e em sucessão às culturas de cobertura do solo em sistema de plantio direto. Bragantia, 67:471-479.

Crusciol CAC, Soratto RP \& Mateus GP (2006) Yield of upland rice cultivars in rainfed and sprinkler-irrigated systems in the Cerrado region of Brazil. Australian Journal of Experimental Agriculture, $46: 1515-1520$.

Embrapa - Empresa Brasileira de Pesquisa Agropecuária (2013) Sistema brasileiro de classificação de solos. $3^{\mathrm{a}}$ ed. Brasília, Embrapa. 353p.

Farooq M, Kobayashi N, Wahid A, Ito O \& Basra SMA (2009) Strategies for producing more rice with less water. Advances in Agronomy, 101:351-389.

Feng LP, Bouman BAM, Tuong TP, Cabangon RJ, Li YL, Lu GA \& Feng YH (2007) Exploring options to grow rice under water-short conditions in northern China using a modeling approach. I: field experiments and model evaluation. Agricultural Water Management, 88:1-13.

Fidelis RR, Rodrigues AM, Silva GF, Barros HB, Pinto LC \& Aguiar RWS (2012) Eficiência do uso de nitrogênio em genótipos de arroz de terras altas. Pesquisa Agropecuária Tropical, 42:124-128.
Freitas RJ, Nascente AS \& Santos FLS (2013) População de plantas de milho consorciado com Urochloa ruziziensis. Pesquisa Agropecuária Tropical, 43:79-87.

Hernandes A, Buzetti S, Andreotti M, Arf O \& Sá ME (2010) Doses, fontes e épocas de aplicação de nitrogênio em cultivares de arroz. Ciência e Agrotecnologia, 34:307-312.

INPE - Instituto Nacional de Pesquisas Espaciais (2014) Previsão de tempo para cidades. Disponível em: <http://www.cptec.inpe.br/cidades/estendida/5123>. Acessado em: 15 de Abril de 2014.

Jadoski SO, Carlesso R, Petry MT, Woishick D \& Cervo L (2000) População de plantas e espaçamento entre linhas do feijoeiro irrigado. I: Comportamento morfológico das plantas. Ciência Rural, 30:559-565.

Kluthcouski J, Aidar H, Thung M \& Oliveira FRA (2006) Manejo antecipado do nitrogênio nas principais culturas anuais. Informações Agronômicas, 113:1-24.

Kumar V \& Ladha JK (2011) Direct seeding of rice: recent developments and future research needs. Advances in Agronomy, 111:297-396.

Marzari V, Marchezan E, Silva LS, Villa SCC, Santos FM \& Teló GM (2007) População de plantas, dose de nitrogênio e aplicação de fungicida na produção de arroz irrigado: II. Qualidade de grãos e sementes. Ciência Rural, 37:936-941.

Mattje VM, Fidelis RR, Aguiar RWS, Brandão DR \& Santos MM (2013) Evaluation of rice cultivars contrasting in doses of nitrogen in soils of irrigated lowland. Journal of Biotechnology and Biodiversity, 4:126133.

Megda MM, Buzetti S, Andreotti M, Teixeira Filho MC \& Vieira MX (2009) Resposta de cultivares de trigo ao nitrogênio em relação às fontes e épocas de aplicação sob plantio direto e irrigação por aspersão. Ciência e Agrotecnologia, 33:1055-1060.

Nascente AS, Crusciol CAC \& Cobucci T (2013a) The no-tillage system and cover crops - alternatives to increase upland rice yields. European Journal of Agronomy, 45:124-131.

Nascente AS, Crusciol CAC, Cobucci T \& Velini ED (2013b) Cover crop termination timing on rice crop production in a no-till system. Crop Science, 53:2659-2669.

Nascente AS, Kluthcouski J, Rabelo RR, Oliveira P, Cobucci T \& Crusciol CAC (2011) Produtividade do arroz de terras altas em função do manejo do solo e da época de aplicação de nitrogênio. Pesquisa Agropecuária Tropical, 41:60-65.

Nascimento V, Arf O, Silva MG, Binotti FFS, Rodrigues RAF \& Alvarez RCF (2009) Uso do regulador de crescimento etil-trinexapac em arroz de terras altas. Bragantia, 68:921-929.

Prasad R (2011) Aerobic rice systems. Advances in Agronomy, 111:207236.

Rodrigues RAF, Soratto RP \& Arf O (2004) Manejo de água em arroz de terras altas no sistema de plantio direto, usando o tanque classe A. Engenharia Agrícola, 24:546-556.

Santos AB, Stone LF \& Vieira NRA (2006) A cultura do arroz no Brasil. $2^{a}$ ed. Santo Antônio de Goiás, Embrapa Arroz e Feijão. 1000p.

Teixeira Filho MCM, Buzetti S, Andreotti M, Arf O \& Benett CGS (2010) Doses, fontes e épocas de aplicação de nitrogênio em trigo irrigado em plantio direto. Pesquisa Agropecuária Brasileira, 45:797-804.

Yoshida S (1981) Fundamentals of Rice Crop Science. Laguna, Los Baños. 269p.

Rev. Ceres, Viçosa, v. 62, n.5, p. 475-482, set-out, 2015 